\title{
Reliability Analysis of I-Section Steel Columns Designed According to New Brazilian Building Codes
}

São Carlos School of Engineering

Structural Engineering Department

13566-590 São Carlos, SP, Brazil

\author{
André S. Dória \\ andre@lccv.ufal.br \\ Federal University of Alagoas - UFAL \\ Scientific Computing and Visualization Laboratory \\ 57072-970 Maceió, AL, Brazil
}

This paper presents an evaluation of the safety of I-section steel columns designed according to the new revision of the Brazilian code for design of steel buildings (NBR8800) and to the code for loads and safety of structures (NBR8681). The safety evaluation is based on structural reliability analysis of columns designed to comply with these codes, and on advanced (FE-based) analysis of actual column resistance. The effects of geometrical imperfections and residual stresses in column resistance are taken into account. The uncertainty in yield stress, elasticity modulus, geometrical imperfections and dead and live loads are considered in the reliability evaluation. Reliability indexes are obtained for several column configurations. These indexes reflect the safety of the columns designed according to the two building codes. Reliability indexes are compared with target reliability indexes used in calibration of the ANSI code and with indexes proposed in the new EUROCODE.

Keywords: steel columns, structural safety, building codes, nonlinear finite element analysis

\section{Introduction}

Design and construction of steel buildings in Brazil is subject to two building codes: the Brazilian code for the design of steel buildings (NBR8800) and the Brazilian code for loads and safety of structures (NBR8681). For the design of steel columns, NBR8800 provides column resistance in consideration of column geometry (type of cross section, slenderness ratio, imperfections) and materials (yield stress, residual stresses). Resistance of the columns is given by curves adjusted to experimental results, and which already incorporate some reserve strength. These curves provide a nominal strength, which already includes a partial safety factor for the resistance.

In a similar way, NBR8681 provides nominal loads to be used in design, partial safety factors for loads and load combination factors.

The design format provided by the two building codes is in essence the Load and Resistance Factor Design (LRFD) format adopted in the American Institute of Steel Construction specifications (AISC, 2005) and in the new EUROCODE (2001), in which the two Brazilian codes were based.

Although it is clear that the purpose of building codes is to provide adequate safety in the design and construction of structures, the level of safety cannot be measured quantitatively based on the codes alone, since they hide a myriad of safety margins and conservative approximations. The two Brazilian codes mentioned, in particular, have been subject to major revisions just recently. NBR8681 has been extensively updated in 2003, and NBR 8800 is currently under revision. None of the codes has been around long enough for a practical verification of the safety of structures designed to comply with them.

This paper provides limited verification of the safety of steel columns designed to comply with NBR8681 and with the revised text of NBR8800. The study is based on structural reliability theory, which allows explicit consideration of the uncertainty that affects performance of constructed structures. Structural reliability analysis results in a quantitative measure of structural safety, given in terms of a failure probability or the related reliability index. This is only a nominal measure of safety, but nevertheless it is the measure used in

Paper accepted February, 2008. Technical Editor: Nestor A. Zouain Pereira. the calibration of major modern design codes (EUROCODE, 2001; AISC, 2005).

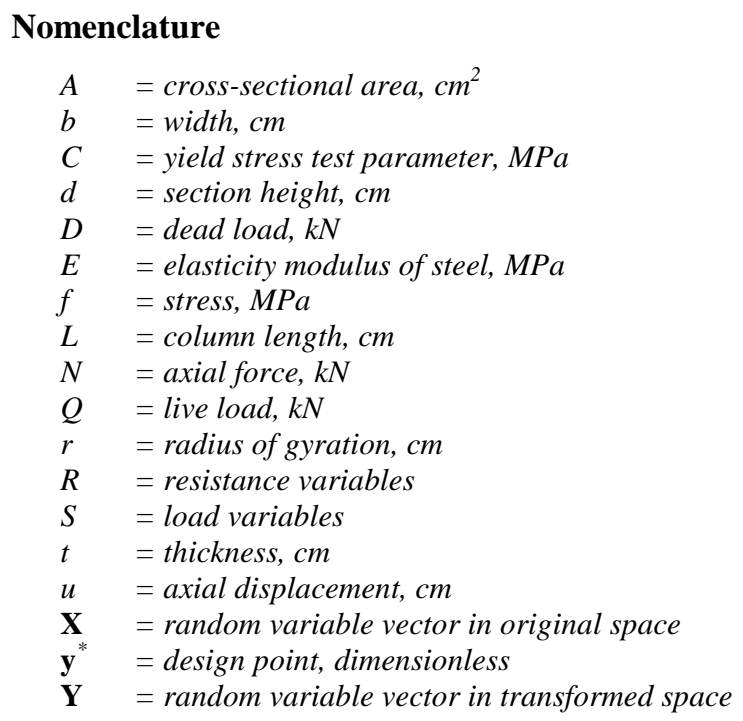

\section{Greek Symbols}

$\alpha \quad=$ sensitivity factor; curve parameter, dimensionless

$\beta \quad=$ reliability index, dimensionless

$\gamma \quad=$ load and resistance factor, dimensionless

$\delta \quad=$ imperfection, $\mathrm{cm}$

$\eta \quad$ = fabrication parameter, dimensionless

$\lambda=$ slenderness, dimensionless

$\Phi=$ cumulative standard normal distribution

$\chi \quad=$ column resistance reduction factor, dimensionless

Subscripts

0 relative to initial condition

$D$ relative to dead load

$f \quad$ relative to section flange; failure

$g$ relative to gross section

$i \quad$ vector index

$n \quad$ relative to nominal value

$Q \quad$ relative to live load

$R \quad$ relative to resistance

$r c$ relative to residual compression 
$R d$ relative to design resistance

$r t$ relative to residual tension

$S \quad$ relative to load

$S d$ relative to design load

$w$ relative to section web

$y \quad$ relative to yielding

yn relative to nominal yield value

\section{Design of Steel Columns Following NBR8800}

The compressive resistance of steel columns is dependent on physical and geometrical properties, which include:

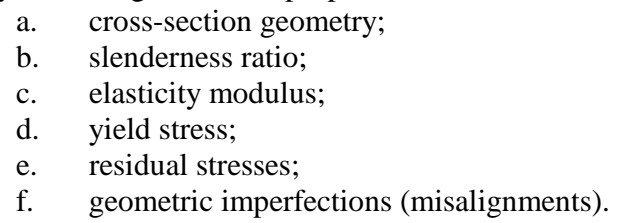

Geometrical imperfection is characterized by the misalignment of a column throughout its length, as shown in Fig. 1. Imperfections are originated in the fabrication process, in transport and storage, and they cause second order bending moments. The tolerance for geometric imperfections in NBR8800 is up to L/1000, where L is the column length (ABNT, 1986 and 2007).

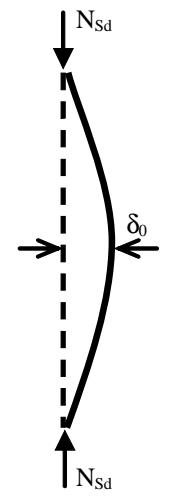

Figure 1. Initial geometric imperfection.

Residual stresses originate in the fabrication process, especially in hot rolled and welded beams. Following Galambos and Ketter (1959), the hot rolling process can originate compressive residual stresses $\left(f_{r c}\right)$ of the order of $30 \%$ of the steel yield stress $\left(0.3 f_{y n}\right)$. Based on experimental results, the authors propose a simplified diagram for the distribution of residual stresses in I section beams, as shown in Fig. 2. More elaborate diagrams exist, which admit non-linear variation of the stresses along the web. However, it is the compressive residual stresses at the flanges that affect compressive resistance of a column. Therefore, the simplified diagram is adopted in this study.

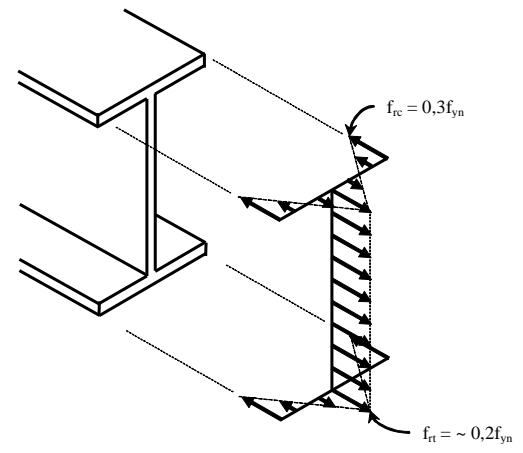

Figure 2. Residual stress distribution in hot rolled I section beams.

Residual stresses, present at a column prior to loading, cause premature plastic deformation when the column is loaded. Clearly, this only happens when the sign of residual and working stresses is the same. Figure 3 shows equilibrium paths of imperfect compressed columns with and without residual stresses. The neglection of residual stresses in this example resulted in a compressive strength $8.9 \%$ greater than the strength obtained by considering residual stresses. This points out to the importance of incorporation residual stresses in the analysis of compressed I-shaped columns.

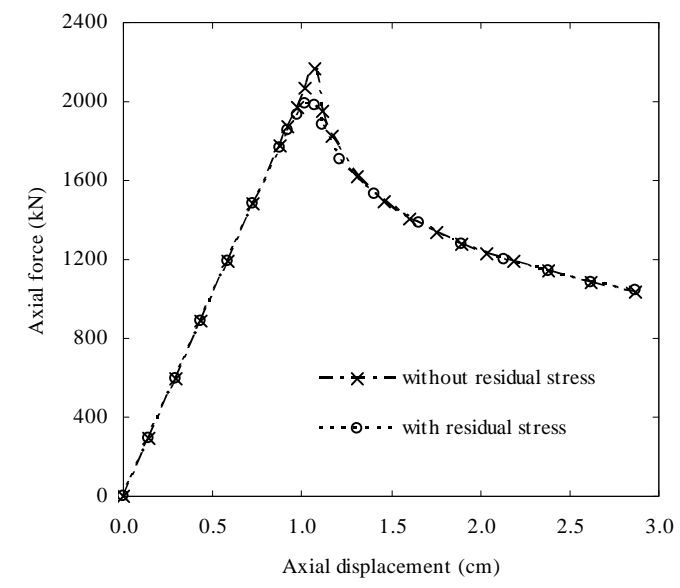

Figure 3. Equilibrium paths for an imperfect I-section beam, with and without consideration of residual stresses.

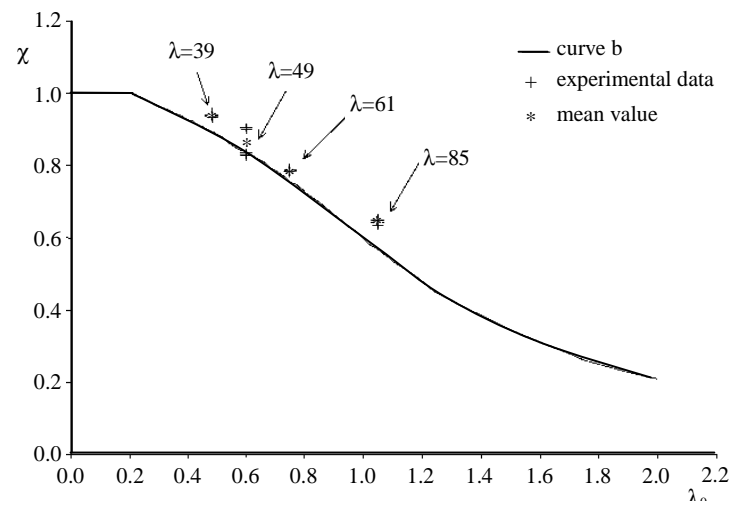

Figure 4. Resistance curves (resistance reduction factor $\chi$ ) for I section columns in compression, NBR8800. 
Column resistance in NBR8800 is given by curves adjusted to experimental results, as shown in Fig. 4 (I section columns). The nominal (design) resistance in NBR8800 is given by general expressions like:

$$
\mathrm{N}_{\mathrm{Rd}}=\chi \mathrm{A}_{\mathrm{g}} \mathrm{f}_{\mathrm{yn}} / \gamma
$$

where $A_{g}$ is the cross-section area, $f_{y n}$ is the nominal value of the steel yield stress, $\gamma$ is a partial safety factor for the resistance (equal to 1.1) and $\chi$ is a reduction factor for the normal load at the column, which takes into account failure due to instability (flexural bending and torsional-flexural bending). Reduction factor $\chi$ shown in Fig. 4 is given by:

$$
\chi=\frac{1}{\beta+\left(\beta^{2}-\lambda_{0}^{2}\right)^{1 / 2}} \leq 1.0
$$

Where

$$
\beta=0.5\left(1+\alpha\left(\lambda_{0}-0.2\right)+\lambda_{0}^{2}\right)
$$

Parameter $\alpha$ represents the influence of residual stresses and initial geometric imperfections. It assumes four different values, giving rise to four compression resistance curves (curves $a$ to $d$ ):

$$
\alpha=\left\{\begin{array}{l}
0.21 \text { curve } a \\
0.34 \text { curve } b \\
0.49 \text { curve } c \\
0.76 \text { curve } d
\end{array}\right.
$$

Curves $a$ and $b$ correspond to instability of I section columns, with respect to the weak and strong axes, respectively. These curves are focused in the present study. Parameter $\lambda_{0}$ is the reduced slenderness ratio, given by:

$$
\lambda_{0}=\lambda\left(\mathrm{f}_{\mathrm{yn}} / \mathrm{E}_{\mathrm{n}}\right)^{1 / 2}
$$

where $\lambda$ is the actual slenderness ratio of the column. This should not be larger than 200, following NBR8800:

$$
\lambda=\mathrm{L} / \mathrm{r} \leq 200
$$

The normative procedure just presented allows the determination of a particular columns resistance, but it does not provide a quantitative estimate of the columns safety. Partial safety factors and conservative approximations are included in resistance curves and in Eq. (1), hence the resulting resistance is a nominal one, already incorporating some reserve strength. In this study, non-linear FE analysis (advanced analysis) is used to represent actual column resistance as closely as possible. It should be noted that the advanced analysis described in the next section is part of the design procedure recommended by the AISC standard (AISC, 2005).

\section{Non-Linear FE Analysis of Column Resistance}

Column resistance is evaluated by means of non-linear FE analysis, including elasto-plastic behavior, geometrical non-linearity, geometrical imperfections and residual stresses. This type of analysis has been called advanced analysis by researches involved in the design of steel buildings (Essa and Kennedy, 2000; Buopanne and Schafer, 2000).
FE analysis is performed in the software ABAQUS 6.5 (Hibbit, Karlsson and Sorenson INC, 2005), with an elastic-perfectly plastic material model and using the von Mises yield criterion. Hinged columns were considered, as shown in Fig. 5. Geometric imperfections were considered explicitly in the FE model. The shape of initial imperfections was assumed parabolic, with random amplitude $\delta_{0}$ at the center of the column. The admitted parabolic shape is more detrimental to column resistance than imperfection randomly distributed over column length; hence the approximation is conservative in terms of column safety.
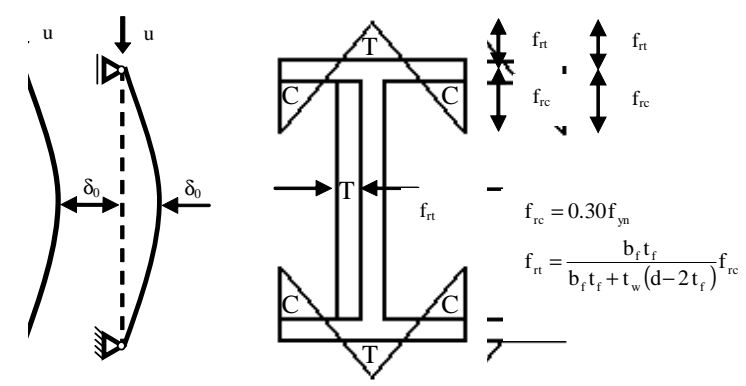

Figure 5. Mechanical model: column geometry and distribution of residual stresses in the cross-section.

Residual stresses are incorporated in the model as a state of self-equilibrated initial stresses (Fig. 5), defined at the cross-section integration points (Fig. 6). A special routine was written in FORTRAN to incorporate the residual stresses in the model. The routine contains values of normal residual stresses for the integration points shown in Figure 6 (right).

Columns were discretized using 10 three-dimensional beam elements (B32) with 6 degrees of freedom per node: three rotations and three displacements. This discretization is sufficient to represent the imperfect parabolic shape of the columns.

The element used has more degrees of freedom than needed in a plane analysis. However, the distribution of integration points in the cross-section justifies the need for a full 3D element. In order to reproduce the residual stress diagram, it is necessary to have integration points at the flanges, as shown in Figure 6.
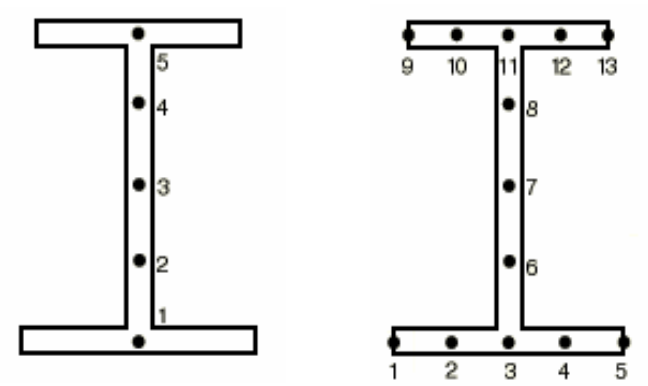

Figure 6. Integration points in the cross-section: plane elements (left) and 3D element (right).

Critical loads for the columns were obtained with displacement control. A total prescribed axial displacement of L/100 was applied incrementally at the top of the column, with "load" steps corresponding to $1 \%$ of the total imposed displacement. The critical load, or column resistance, is obtained as the critical point in the equilibrium path, as shown in Figure 3.

Numerical models were first validated by comparing numerically predicted column strength with column strength 
obtained from Brazilian standard NBR8800. Two situations were analyzed:

a. lateral instability due to buckling with respect to the weak axis (resistance curve $a$ with $\alpha=0.21$ ) and;

b. instability due to buckling with respect to the strong axis (resistance curve $b$ with $\alpha=0.34$ ).

Considered material properties are $\mathrm{f}_{\mathrm{yn}}=350 \mathrm{MPa}$ and $\mathrm{E}_{\mathrm{n}}=205000$ $\mathrm{MPa}$. Geometrical properties of the cross-section are shown in Fig. 7.

Results for buckling with respect to both axes are presented in Fig. 8. It is clear in Fig. 8 that the non-linear FE model considered properly represents column resistance (or the resistance reduction factor) for the whole range of slenderness ratios (remind that code curves are based on experimental results). It can also be seen that nominal (normative) resistances either match or are slightly smaller than numerically predicted resistances. This is to be expected since code curves are always drawn as conservative bounds to experimental results.

Flexural buckling about $\mathrm{x}-\mathrm{x}$ axis

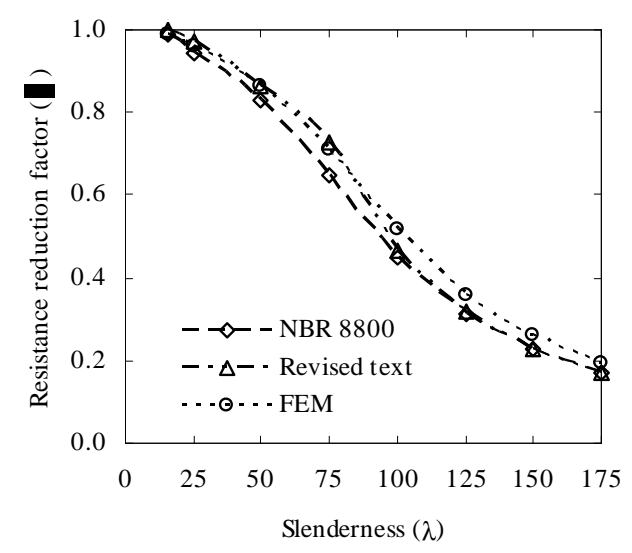

Table 1 shows the deviation of nominal resistances (NBR8800 and revised text of same standard) from numerically predicted column resistance.

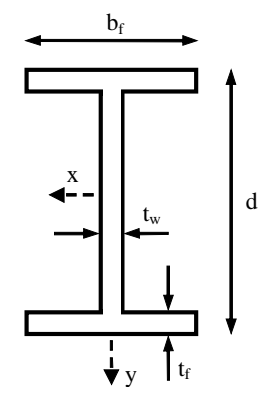

$$
\begin{aligned}
& \mathrm{d}=35.31 \mathrm{~cm} \\
& \mathrm{~b}_{\mathrm{f}}=25.38 \mathrm{~cm} \\
& \mathrm{t}_{\mathrm{f}}=1.64 \mathrm{~cm} \\
& \mathrm{t}_{\mathrm{w}}=0.95 \mathrm{~cm}
\end{aligned}
$$

Figure 7. Geometrical properties of the cross-section.

Flexural buckling about y-y axis

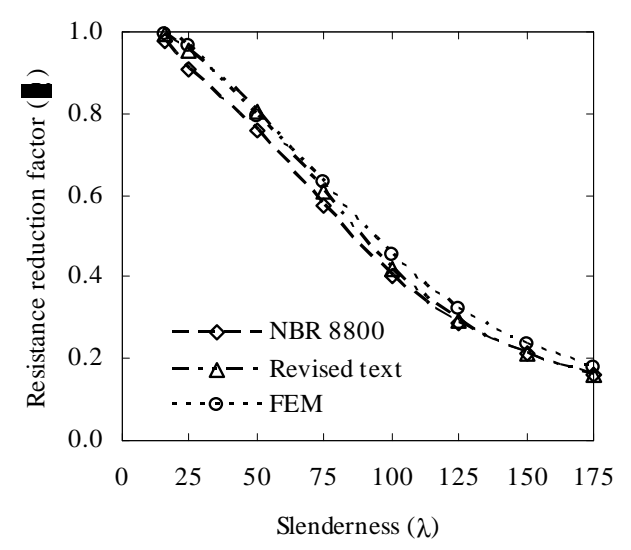

Figure 8. Comparison of column resistance.

Table 1. Deviation (\%) of nominal resistances from numerically predicted column strength.

\begin{tabular}{|c|c|c|c|c|}
\hline \multirow{2}{*}{} & \multicolumn{2}{|c|}{ Buckling about strong axis (x-x) } & \multicolumn{2}{c|}{ Buckling about weak axis (y-y) } \\
\cline { 2 - 5 } & NBR 8800 & Revised text & NBR 8800 & Revised text \\
\hline 25 & -0.9 & -1.1 & 4.9 & 1.5 \\
\hline 50 & 0.9 & -1.0 & 3.5 & -1.5 \\
\hline 75 & 2.7 & -0.5 & 8.2 & 3.3 \\
\hline 100 & 8.1 & -2.8 & 9.7 & 7.1 \\
\hline 125 & 11.8 & 9.6 & 9.4 & 7.9 \\
\hline 150 & 12.4 & 11.5 & 10.5 & 9.7 \\
\hline 175 & 12.0 & 11.7 & 10.3 & 9.9 \\
\hline
\end{tabular}

\section{Structural reliability analysis}

Column design and actual column performance in constructed facilities depends on several uncertain or random parameters. These include, but are not limited to, material resistance (yield stress and elasticity modulus), geometric imperfections, state of residual stresses, boundary conditions, self weight and service loads. Structural reliability analysis allows this uncertainty to be explicitly taken into account, and a quantitative measure of structural safety to be derived.

The structural reliability analysis of columns designed to comply with NBR8800 and NBR8681 can be summarized as follows. For each column configuration considered:

a. nominal resistance (strength) of the column is evaluated from Eq. 1 and design curves (NBR8800); b. axial load at the column is chosen so that design load is equal to design resistance (NBR8681);

c. structural reliability analysis is performed, considering not the nominal or design values of load and resistance, but representing design parameters as random variables, and evaluating column resistance by means of non-linear FE analysis.

These steps are described in detail in the sequence.

\section{Limit State Equation}

Random problem parameters are grouped in vector $\mathbf{X}$. For the purpose of illustration, this vector can be separated in a vector of resistance random variables $\left(\mathbf{X}_{\mathrm{R}}\right)$ and a vector of load random variables $\left(\mathbf{X}_{\mathrm{S}}\right)$. A limit state equation is written in terms of these variables in such a way as to divide the failure and safety domains:

$$
\mathrm{g}(\mathbf{X})=\mathrm{R}\left(\mathbf{X}_{\mathrm{R}}\right)-\mathrm{S}\left(\mathbf{X}_{\mathrm{S}}\right)=0
$$

In Eq. (7), $R\left(\mathbf{X}_{R}\right)$ is the strength (resistance) of the column, evaluated by non-linear FE analysis, and $\mathbf{S}\left(\mathbf{X}_{\mathrm{S}}\right)$ is the actual column load. Column load can be obtained as a sum of individual loads, as will be seen in the sequence:

$$
\mathrm{S}\left(\mathbf{X}_{\mathrm{S}}\right)=\sum \mathrm{X}_{\mathrm{S}}
$$

Data on random variables probability distributions and distribution parameters is obtained from international references 
such as (Galambos and Ravindra, 1978; Vrouwenvelder, 2002 and Ellingwood et al., 1980).

\section{Resistance Random Variables}

Following Vrouwenvelder (2002), the yield stress of structural steel can be described by a log-normal distribution with C.O.V. $=0.07$ and mean given by:

$$
E\left[f_{y}\right]=f_{y n} \eta e^{-u v}-C
$$

where:

$\mathrm{f}_{\mathrm{yn}}$ is the nominal resistance;

$\eta=1.05$ for the web of hot rolled sections and $\eta=1.0$ otherwise;

$\mathrm{u}$ is a parameter that varies between -1.5 and -2.0 , depending on the steels production process;

$\mathrm{C}$ is a constant that takes into account the difference between yield stresses obtained in mill and static testing; recommended value is $\mathrm{C}=20 \mathrm{MPa}$.

In this paper, the value $\eta=1$ is used, since the contribution of the web in the bending resistance of the column is less significant than the contribution of the flanges. Therefore, it is considered more appropriate to use the value of $\eta$ corresponding to the flanges. Due to the lack of more specific recommendation, parameter $u$ was set as the medium value of the suggested range $(u=-1.75)$. Substituting these values in Eq. 9, one obtains $E\left[f_{y}\right]=1.05 f_{y n}$, which coincides with the mean value proposed by Galambos and Ravindra (1978).

The log-normal distribution is appropriate to represent yield stresses because these have to be strictly positive.

For the modulus of elasticity, a log-normal distribution is considered, with mean $E_{n}$ and C.O.V. $=0.03$ as suggested in Vrouwenvelder (2002).

\section{Load Random Variables}

The design value of the compressive load in the column is obtained as:

$$
\mathrm{N}_{\mathrm{Sd}}=\mathrm{N}_{\mathrm{Rd}}
$$

where $\mathrm{N}_{\mathrm{Rd}}$ is the column strength given by Eq. 1. The normal compressive load $\left(\mathrm{N}_{\mathrm{Sd}}\right)$ acting on the columns is considered as being the sum of a dead and a live load:

$$
\mathrm{N}_{\mathrm{Sd}}=\gamma_{\mathrm{D}} \mathrm{D}_{\mathrm{n}}+\gamma_{\mathrm{Q}} \mathrm{Q}_{\mathrm{n}}
$$

where $\gamma_{D}$ and $\gamma_{Q}$ are partial factors for dead and live loads, respectively. For the self-weight of steel structures, NBR8681 gives $\gamma_{D}=1.35$. When variable actions are grouped, the factor $\gamma_{Q}=1.5$ is suggested. This results in:

$$
\mathrm{N}_{\mathrm{Sd}}=1.35 \mathrm{D}_{\mathrm{n}}+1.5 \mathrm{Q}_{\mathrm{n}}
$$

Eqs. (10) and (12) are not sufficient to establish the nominal values $D_{n}$ and $Q_{n}$ of the loads. A proportionality relation between these loads is needed in order to determinate both from known $\mathrm{N}_{\mathrm{Sd}}$. In this study, the relations $\mathrm{Q}_{\mathrm{n}}=\mathrm{D}_{\mathrm{n}}, \mathrm{Q}_{\mathrm{n}}=2.5 \mathrm{D}_{\mathrm{n}}$ and $\mathrm{Q}_{\mathrm{n}}=5.0 \mathrm{D}_{\mathrm{n}}$ are investigated.

Probability distributions and distribution parameters for loads are given by Ellingwood et al. (1980). Dead load is represented as a normal distribution with C.O.V.=0.10. The live load is represented by an extreme Type I distribution, with mean $0.95 \mathrm{Q}_{\mathrm{n}}$ and C.O.V. $=0.25$.

The nominal values $D_{n}$ and $Q_{n}$ of the loads are also given in NBR8681. The nominal value of dead loads has a $50 \%$ chance of being exceeded. This results in $E[D]=D_{n}$. The nominal value of live loads should only be exceeded with $25 \%$ to $35 \%$ probability. Adopting a confidence level of $65 \%$, with a Type I (Gumbel) distribution and C.O.V. $=0.25$, this results in $E[Q]=0.95 Q_{n}$.

A summary of random variables, their probability distributions and parameters is shown in Table 2 .

Table 2. Probability distribution and parameters of random variables.

\begin{tabular}{|l|l|l|l|l|}
\hline Variable & Symbol & Distribution & E[.] & C.O.V. \\
\hline Initial geometric imperfection & $\delta_{0}$ & normal & 0.00 & $-^{\text {(a) }}$ \\
\hline Yield stress & $\mathrm{f}_{\mathrm{y}}$ & log-normal & $1.05 \mathrm{f}_{\mathrm{yn}}$ & 0.07 \\
\hline Elasticity modulus & $\mathrm{E}$ & log-normal & $1.00 \mathrm{E}_{\mathrm{n}}$ & 0.03 \\
\hline Dead load & $\mathrm{D}$ & normal & $1.00 \mathrm{D}_{\mathrm{n}}$ & 0.10 \\
\hline Live load & $\mathrm{Q}$ & Gumbel & $0.95 \mathrm{Q}_{\mathrm{n}}$ & 0.25 \\
\hline
\end{tabular}

(a) Standard deviation equal to $\mathrm{L} / 1000$

\section{Computation of the Reliability Index}

Computation of the failure probability basically amounts to evaluating the multi-dimensional integral (Melchers, 1999):

$$
P_{f}=\int_{g(\mathbf{x} \leq \leq 0} f_{\mathbf{x}}(\mathbf{x}) d \mathbf{x}
$$

where $f_{\mathbf{X}}(\mathbf{x})$ is the joint probability density function of the problems random variables.

In the First Order Reliability Method (FORM), the solution of equation (13) involves a transformation of random variable vector $\mathbf{X}$ into a set of uncorrelated standard Gaussian variables $\mathbf{Y}$, as well as a search for the theoretically most probable failure point (known as design point, $\left.\mathbf{y}^{*}\right)$. In the transformed space of $\mathrm{Y}$, the most probable failure point $\mathbf{y}^{*}$ becomes the point over the limit state surface closest to the origin. The distance of the design point to the origin in the transformed space is known as reliability index $(\beta)$. At the design point $\mathbf{y}^{*}$, the limit state function is linearized, yielding the FORM approximation of the failure probability as:

$$
P_{f}=\Phi(-\beta)
$$

where $\Phi($.$) is the cumulative standard Gaussian distribution and \beta$ is the reliability index. Details of the formulation are omitted here but can be found elsewhere (Melchers, 1999; Beck and da Rosa, 2006).

A particularity of the reliability problem solved in this paper is the fact that limit state equation $g(\mathbf{X})=0$ is not given in closed form. In this paper, the limit state equation is given numerically as a solution of a non-linear FE model:

$$
\begin{aligned}
\mathrm{g}(\mathbf{X}) & =\mathrm{R}\left(\mathbf{X}_{\mathrm{R}}\right)-\mathrm{S}\left(\mathbf{X}_{\mathrm{S}}\right)=0 \\
& =\mathrm{R}\left(\delta_{0}, \mathrm{f}_{\mathrm{y}}, \mathrm{E}\right)-(\mathrm{D}+\mathrm{Q})=0
\end{aligned}
$$

where $\mathrm{R}\left(\mathbf{X}_{\mathrm{R}}\right)$ is the resistance of the column, evaluated by non-linear FE analysis.

This means that algorithms for the solution of the structural reliability problem have to be implemented in the FE program, just as described by Beck and da Rosa (2006). With this purpose, an object-oriented computational code was developed in Python. This code contains routines to:

a. perform the necessary transformation to the standard Gaussian space;

b. evaluate gradients of the limit state function;

c. search for the design point using the HLRF algorithm;

d. evaluate the reliability index and estimate the failure probability. 
The numerical limit state equation is evaluated through a sub-routine (script) that solves the structural problem and searches for the critical load $\mathrm{R}\left(\mathbf{X}_{\mathrm{R}}\right)$ in the equilibrium path. This is then used to evaluate the limit state function (Eq. 15).

The structural reliability analysis is performed in the ABAQUS environment, since the program is capable of interpreting the Python algorithms, as well as executing the script to create and solve the mechanical model. The subroutine that evaluates the residual stresses is compiled at the beginning of each analysis. Figure 9 displays the organization of the algorithmic procedures required in the solution of the reliability problem.

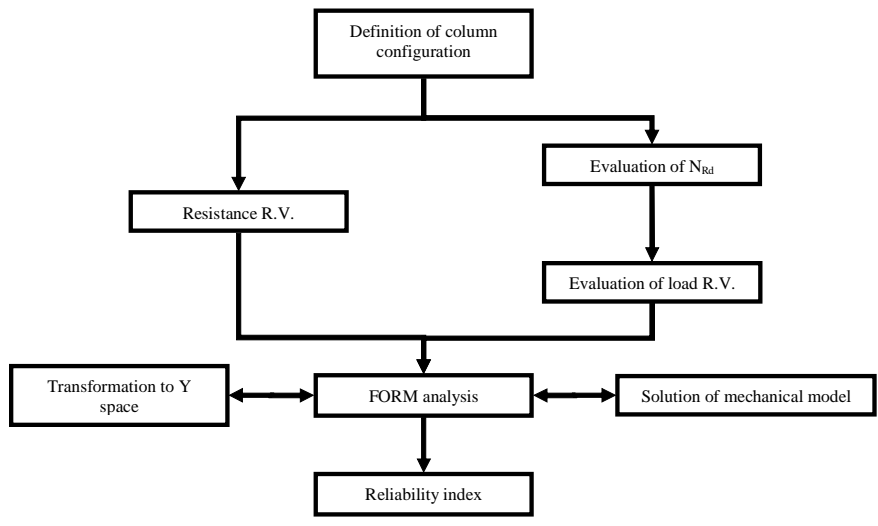

Figure 9. Flowchart of structural reliability analysis (R.V.=random variables).

\section{Results}

The methodology just described was employed to evaluate the reliability of columns designed according to the standards NBR8800 and NBR8681. A total of 48 representative column configurations were analyzed.

Two nominal values of steel yield strength $\left(f_{\mathrm{yn}}\right)$ were considered: 250 and $350 \mathrm{MPa}$. Elasticity modulus was set as $E_{n}=205000 \mathrm{MPa}$ and the proportionality of dead to live load was first set to $Q_{n}=D_{n}$. Eight cases of slenderness ratios were analyzed, with values ranging from $\lambda=25$ to $\lambda=200$ (the maximum allowed value). Properties of the cross-section are shown in Fig. 7.

Reliability index results $(\beta)$ are presented in Figs. 10 and 11 as functions of slenderness $(\lambda)$ for the two values of $f_{y n}$. Fig. 10 shows results for buckling with respect to the major $(\mathrm{x}-\mathrm{x})$ axis and Fig. 11 shows results for buckling with respect to the minor (y-y) axis. The figures show reliability indexes that are reasonably uniform over the range of slenderness ratios, as well as between buckling directions.
Flexural buckling about $\mathrm{x}-\mathrm{x}$ axis

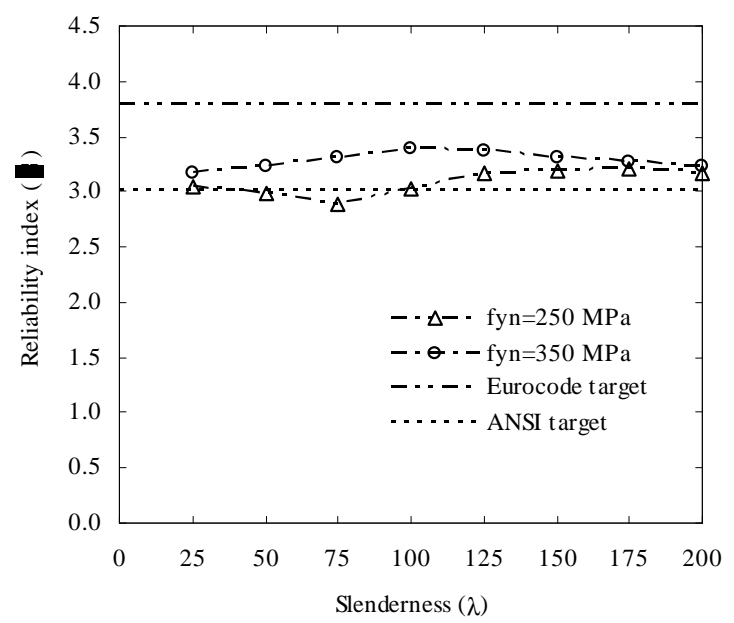

Figure 10. Reliability index $(\beta)$ as a function of slenderness ratio $(\lambda)$ of columns subject to compression ( $x-x$ axis).

This uniformness of reliability indexes is provided by the resistance curves of NBR8800. The uniformness is not quite the same in terms of nominal yield stresses.

The reliability indexes shown in Figures 10 and 11 are compared with two target reliability values. Annex $\mathrm{C}$ of the new EUROCODE (2001) suggests a minimum of $\beta=3.8$ for the medium consequence class (e.g., design of office and residential buildings) and a 50 year reference period. The American (ANSI) code for actions on structures was calibrated to $\beta_{\text {target }}=3.0$ for the D+Q load combination (Ellingwood et al., 1980).

Figures 10 and 11 show that safety of columns designed according to Brazilian codes compares favorably with the ANSI reliability target for the load ratio $\mathrm{Q}_{\mathrm{n}}=\mathrm{D}_{\mathrm{n}}$. Reliability indexes are below the EUROCODE target, but our experience tells that this target is hardly met in current practice (Oliveira et al., to appear).

Two more critical dead-to-live load combinations were also considered. The ratios $\mathrm{Q}_{\mathrm{n}}=2.5 \mathrm{D}_{\mathrm{n}}$ and $\mathrm{Q}_{\mathrm{n}}=5.0 \mathrm{D}_{\mathrm{n}}$ were analyzed, but only for the most critical cases of flexural buckling about $y-y$ axis and $\mathrm{f}_{\mathrm{yn}}=250 \mathrm{MPa}$. These results are shown in Fig. 12.

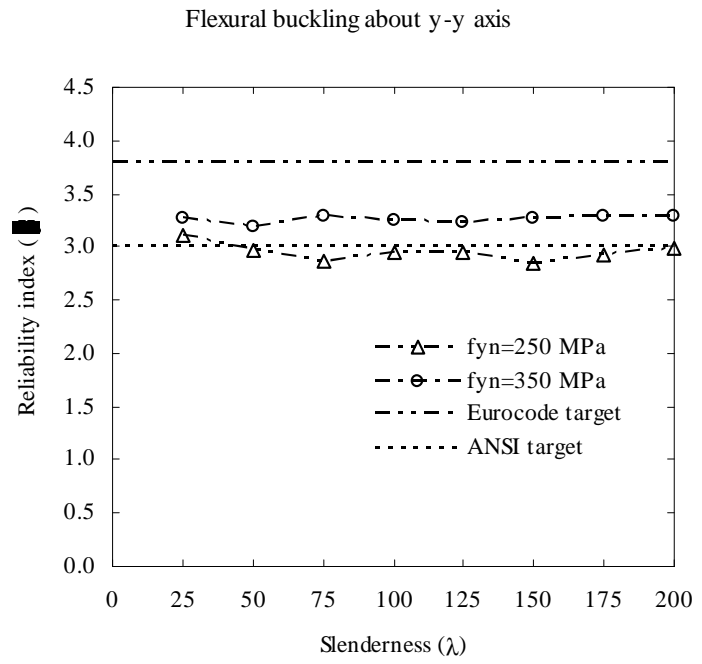

Figure 11. Reliability index $(\beta)$ as a function of slenderness ratio $(\lambda)$ of columns subject to compression ( $y$-y axis). 
In Fig. 12 it is observed that reliability indexes drop considerably in comparison to the case $\mathrm{Q}_{\mathrm{n}}=\mathrm{D}_{\mathrm{n}}$. This result was already expected, and it is a consequence of the fact that column reliability is more sensitive to live load (extreme value distribution with C.O.V.=0.25) then to dead load (normal distribution with C.O.V.=0.10). This result is also a consequence of the fact that in modern design codes the same partial load factors are used regardless of the dead-to-live load ratios. However, this reduction on reliabilities can also be credited to the specific partial factors adopted in NBR8681. The American code (ASCE, 2006) uses $\gamma_{D}=1.2$ and $\gamma_{Q}=1.6$, whereas the Brazilian code (NBR8681) uses $\gamma_{D}=1.35$ and $\gamma_{Q}=1.5$. In our opinion, the coefficients used in the American code better reflect the uncertainty in these loads (greater variability of the live load in comparison to dead load). As a consequence, the American code is able to maintain more uniform reliability when load ratios change (Ellingwood et al., 1980). Since reliability results using the Brazilian codes dropped considerably bellow the ANSI target $(\beta=3.0)$, the NBR8681 and NBR8800 code committees should look carefully to the present results. Perhaps a reconsideration of partial factors for loads is needed. A reliability index of 2.5 corresponds to a nominal failure probability of $6.210^{-3}$. Whether this is enough or not is a matter left for interpretation by the code committee or by the reader.

Flexural buckling about $y-y$ axis

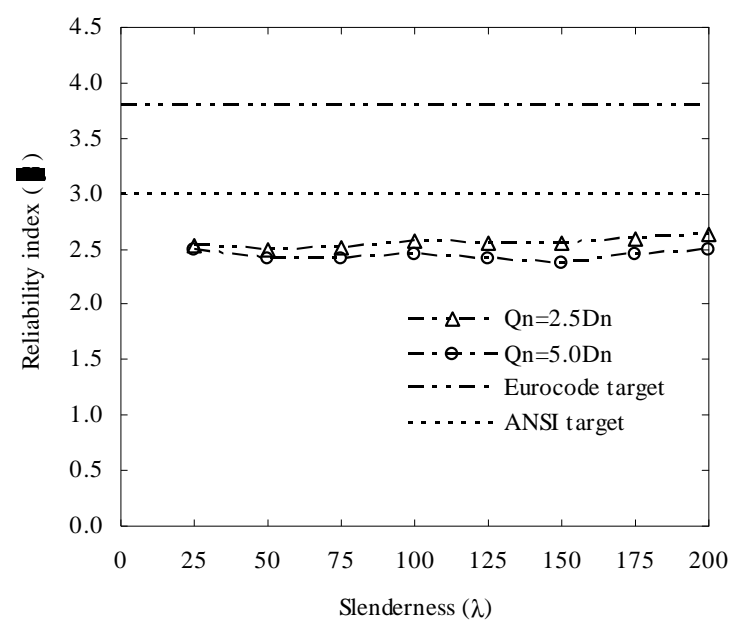

Figure 12. Reliability index ( $\beta$ ) for different dead (D) to live load $(Q)$ ratios.

Important sub-products of a FORM reliability analysis are the sensitivity coefficients $\left(\boldsymbol{\alpha}_{\mathrm{i}}\right)$, which give the contribution of individual random variables in the failure probability. In the transformed space Y, sensitivity coefficients are simply evaluated as:

$$
\boldsymbol{\alpha}=\frac{\nabla \mathrm{g}\left(\mathbf{y}^{*}\right)}{\left\|\nabla \mathrm{g}\left(\mathbf{y}^{*}\right)\right\|}
$$

where $\mathrm{g}\left(\mathbf{y}^{*}\right)$ is the gradient of the limit state function in $\mathrm{Y}$ space evaluated at the design point. Sensitivity coefficients vary in the range $\{-1,1\}$. Negative values represent "load" variables, since an increase in these variables produces a decrease in the limit state function. Positive sensitivity coefficients represent "resistance" variables. The absolute value of the sensitivity coefficient is a measure of the contribution of the random variable towards the failure probability.
Figure 13 shows sensitivity coefficients $\left(\boldsymbol{\alpha}_{\mathrm{i}}\right)$ for the curve $\mathrm{f}_{\mathrm{yn}}=350 \mathrm{MPa}$, buckling with respect to the strong axis $(\mathrm{x}-\mathrm{x})$ and for the case $Q_{n}=D_{n}$. Similar results are obtained for the other design configurations studied in the paper.

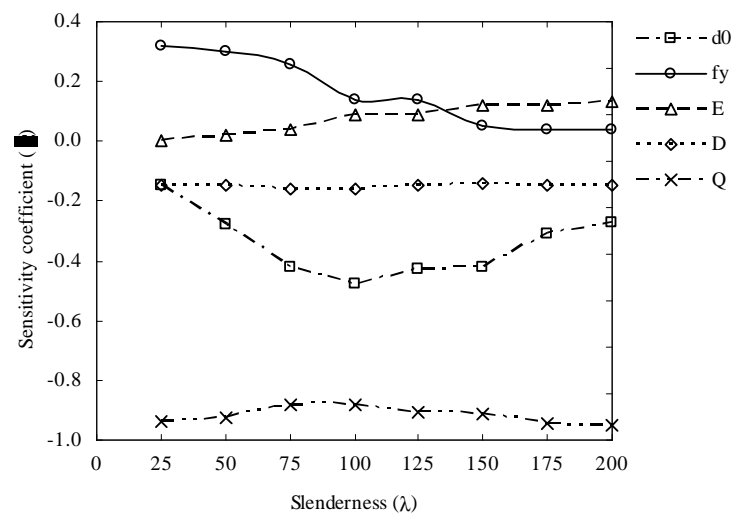

Figure 13. Sensitivity coefficients of the problems random variables.

It is significant to observe that, as the slenderness of the column increases, the contribution of yield stress uncertainty decreases and the contribution of elasticity modulus increases. This result reflects physical behavior of the problem, since columns of small slenderness fail under high levels of plastification (squashing), whereas columns with larger slenderness fail elastically.

Results in Figure 13 also show that the uncertainty in initial imperfections is quite significant.

Figure 13 also shows that influence of live load (Q) in failure probabilities is larger than the influence of dead load (D), even when they have the same nominal value $\left(D_{n}=Q_{n}\right)$. Clearly, this is a consequence of the larger variability of live loads (25\% comparing to $10 \%$ variability of dead loads). This result is also a consequence of the fact that live load is represented by an extreme value distribution, which has higher probability content at the upper tail when compared with the normal distribution of the dead load. The significant contribution of live load uncertainty to failure probabilities explains the drop in reliability indexes for load ratios $\mathrm{Q}_{\mathrm{n}}=2.5 \mathrm{D}_{\mathrm{n}}$ and $\mathrm{Q}_{\mathrm{n}}=5.0 \mathrm{D}_{\mathrm{n}}$, as shown earlier.

\section{Discussion}

The results observed in Figures 10 to 12 should not come as a complete surprise. In fact, what one can observe in these results is the closing of a loop that started in the definition of partial safety factors, based on target reliability indexes, of both the American and the European structural design codes. Brazilian code NBR8800 is largely derived from the American code (AISC, 2005), but uses compression resistance curves based on European experimental results. The structural loads code (NBR8681), on the other hand, is heavily based on the European code, from which most partial safety factors for loads were derived. For the $D_{n}=Q_{n}$ load ratio, the Brazilian codes still reflect the target reliability index used in calibration of the American codes. For other load ratios $\left(Q_{n}=2.5 D_{n}\right.$ and $\mathrm{Q}_{\mathrm{n}}=5.0 \mathrm{D}_{\mathrm{n}}$ ), however, the Brazilian codes may be resulting in insufficient reliability. In order to make this a more definite conclusion, however, studies on the variability of live loads in the actual Brazilian reality would be needed.

Reliability indexes presented in this paper are nominal measures of safety (Melchers, 1999). These indexes are representative of the safety introduced by codified design, but they do not necessarily represent the reliability of actual constructed structures. 


\section{Conclusions}

This paper presented a procedure to evaluate the safety of steel columns designed to comply with the Brazilian building codes NBR8800 and NBR8681. The procedure involves a non-linear FE analysis of column resistance, including effects of residual stresses, initial imperfections, and plastic failure of the columns. It also involves a structural reliability analysis for the reliability index of the columns. A computational code was developed in ABAQUS to perform reliability analysis of the columns.

Several column configurations were analyzed. Numerical column resistance results were first compared with the resistance curves of NBR8800. Loads were then obtained following NBR8681. Probabilistic data on the problems random variables was collected from the literature.

The results obtained in the paper show that I-section columns designed according to the two building codes present adequate levels of safety for load ratio $\mathrm{Q}_{\mathrm{n}}=\mathrm{D}_{\mathrm{n}}$. Resistance curves used in NBR8800 provide uniform reliability over the allowed range of slenderness ratios and over buckling directions. This uniformness is not the same in terms of steels yielding stresses.

For other load ratios common in steel design $\left(\mathrm{Q}_{\mathrm{n}}=2.5 \mathrm{D}_{\mathrm{n}}\right.$ and $\mathrm{Q}_{\mathrm{n}}=5.0 \mathrm{D}_{\mathrm{n}}$ ), however, the reliability proportioned by Brazilian codes may be insufficient. This is mainly due to the partial load factors adopted in NBR8681. In the authors opinion, partial factors $\gamma_{D}=1.35$ and $\gamma_{\mathrm{Q}}=1.5$ do not properly reflect the uncertainty and variability of these loads. As a consequence, the Brazilian code NBR8681 does not provide uniform reliability over distinct load ratios.

These conclusions reflect the safety of I-section steel columns studied in the paper. More definite conclusions would require an extensive study of other structural applications, as well as further study into uncertainty of dead and live loads in actual Brazilian reality.

\section{Acknowledgments}

The financial support of this research by the Brazilian Council for Research and Development (CNPq) is greatly appreciated.

\section{References}

ABNT - Associação Brasileira de Normas Técnicas, 1986, "NBR 8800: Design and Construction of Structural Steel Buildings: limit states method" (In Portuguese), Rio de Janeiro.

ABNT - Associação Brasileira de Normas Técnicas, 2003, "NBR 8681: Loads and Safety of Structures" (In Portuguese), Rio de Janeiro.

ABNT - Associação Brasileira de Normas Técnicas, 2007, "NBR 8800 -

Revised Draft: Design and Construction of Structural Steel and Steel-Concrete Buildings: limit states method" (In Portuguese), Jan. 2007.

AISC - American Institute of Steel Construction, 2005. "AISC 360-05: Specification for Structural Steel Buildings".

ASCE - American Society of Civil Engineering, 2006: "Minimum Design Loads for Buildings and Other Structures".

Beck, A.T. and da Rosa, E., 2006, "Structural Reliability Analysis Using Deterministic Finite Element Programs", Latin American Journal of Solids and Structures. v.3, p.197-222.

Buopanne, S.G. and Schafer, B.W., 2000, "Reliability of Steel Frames Designed with Advanced Analysis", Journal of Structural Engineering, Vol. 132, n.2, pp. 267-276.

Ellingwood, B. and Galambos, T.V., 1982, "Probability-based criteria for structural design", Structural Safety 1, pp. 15-26.

Ellingwood, B., Galambos, T.V., MacGregor, J.G. and Cornell, C.A., 1980, "Development of a Probability Based Load Criterion for American National Standard A58", Washington.

Essa H.S. and Kennedy, D.J.L., 2001, "Proposed Provisions for the Design of Steel Beam-Columns in S16-2001", Canadian Journal of Civil Engineering, Vol. 27, pp. 610-619.

EUROCODE, 2001, "prEN 1990: Basis of Structural Design - Annex C: Basis for Partial Factor Design and Reliability Analysis". European Committee for Standardization, Brussels, "Final Draft".

Galambos, T.V. and Ketter, R.L., 1959, "Columns under Combined Bending and Thrust", Journal of the Engineering Mechanics Division, ASCE, Vol. 85, no. EM2, pp. 1-30.

Galambos, T.V. and Ravindra, M.K., 1978, "Properties of Steel for Use in LRFD", Journal of the Structural Division. ASCE, Vol. 104, no. ST9, pp.1371-1468.

Hibbit, Karlsson and Sorenson INC, 2005, “ABAQUS Analysis User's Manual".

Melchers, R.E., 1999, "Structural Reliability Analysis and Prediction", 2nd edition, John Wiley and Sons, NY.

Oliveira, W.L.A; Beck, A.T.; El Debs, A.L.H.C and Nardin, S.D., to apear: "Safety evaluation of concrete-filled steel tubular columns designed according to Brazilian building code NBR 8800:2007“", to appear in Revista IBRACON de Estruturas.

Vrouwenvelder, A.C.W.M., 2002, "Developments towards full probabilistic design codes", Structural Safety, Vol. 24, pp. 417-432. 